\title{
STUDI KERUNTUHAN AKIBAT BEBAN SIKLIK DENGAN METODE ANALISA PUSHOVER PADA PORTAL
}

\author{
Oleh : Arman Setiawan ${ }^{1)}$
}

\begin{abstract}
As the development of technological advances in the field of civil engineering, came new concepts and methods of analysis and planning in earthquake resistant building one concept of Performance Based Seismic Evaluation (PBSE) by the method of analysis of static thrust load or Pushover analysis. This method is able to provide information patterns exist when the buildings collapse burdened earthquake forces that exceed the capacity of the building.

The purpose of writing final task is to re-evaluate the earthquake resistance performance of the three storey building portal to determine the capacity of effective structures and earthquake behavior by showing the scheme of plastic joints on the beam and column elements with the method based on the rules code Pushover Applied Technology Council (ATC-40) and determine the level structural performance of earthquake resistance based those the rules.

From the results of the study, structure capable of providing non-linear behavior indicated the initial phase and the majority of the plastic joints occur in the new block elements and column elements. Performance level in the structure of Immediate Occupancy criteria which means a little damage on structural and the building can be used again.
\end{abstract}

\section{Key words: Pushover, Performance Based Seismic Evaluation (PBSE).}

\section{PENDAHULUAN}

\subsection{Latar Belakang Masalah}

Peristiwa tahun 2006 lalu terjadi gempa dengan kekuatan besar di daerah Jogjakarta dan pada tahun 2009 terjadi di Tasikmalaya serta di Padang yang banyak menimbulkan kerusakan fatal pada bangunan dengan berbagai macam pola keruntuhan. Hal ini menegaskan pentingnya tinjauan beban gempa rencana dalam perencanaan desain struktur sebagai antisipasi apabila terjadi gempa, struktur bangunan mampu menerima gaya gempa pada level tertentu tanpa terjadi kerusakan yang

\footnotetext{
1) Dosen Teknik Sipil Universitas 45 Makassar
} 
signifikan pada strukturnya atau apabila struktur bangunan harus mengalami keruntuhan (disebabkan beban gempa melebihi beban gempa rencana), mampu memberikan perilaku nonlinear pada kondisi pascaelastik sehingga tingkat keamanaan bangunan terhadap gempa dan keselamatan jiwa penghuninya lebih terjamin.

Yosafat Aji Pranata (2006) menyatakan analisa pushover adalah suatu analisis statik nonlinier dimana pengaruh gempa rencana terhadap struktur bangunan gedung dianggap sebagai beban-beban statik yang menangkap pada pusat massa masing-masing lantai, yang nilainya ditingkatkan secara berangsur-angsur sampai melampaui pembebanan yang menyebabakan terjadinya pelelehan (sendi plastis) pertama di dalam struktur bangunan gedung, kemudian dengan peningkatan beban lebih lanjut mengalami perubahan bentuk pasca-elastik yang besar sampai mencapai kondisi elastik. Kemudian disusul pelelehan (sendi plastis) di lokasi yang lain di struktur tersebut.

Perkembangan teknologi sangat membantu civil engineer dalam perencanaan dan analisis terhadap kinerja suatu struktur bangunan. Tersedianya program SAP 2000 mampu menyederhanakan persoalan dalam bentuk pemodelan yang sebelumnya sangat kompleks apabila dikerjakan secara konvensional.

\subsection{Tujuan Penelitian}

Tujuan penelitian ini adalah untuk menganalisis studi keruntuhan bangunan gedung akibat beban siklik dengan metode analisa pushover menggunakan bantuan program SAP 2000 dan kemudian mengkaji dan membahas output yang dihasilkan program tersebut.

\section{KAJIAN PUSTAKA}

\subsection{Analisa Push Over}

Proses perencanaan tahan gempa berbais kinerja dimulai dengan membuat model rencana bangunan kemudian melakukan simulasi 
kinejanya terhadap berbagai kejadian gempa. Setiap simulasi memberikan informasi tingkat kerusakan (level of damage), ketahanan struktur, sehingga dapat memperkirakan berapa besar keselamatan (life), kesiapan di pakai (occupancy) dan kerugian harta benda (economic loss) yang akan terjadi. Perencana selanjutnya dapat mengatur ulang resiko kerusakan yang dapat diterima sesuai dengan resiko biaya yang dikeluarkan.

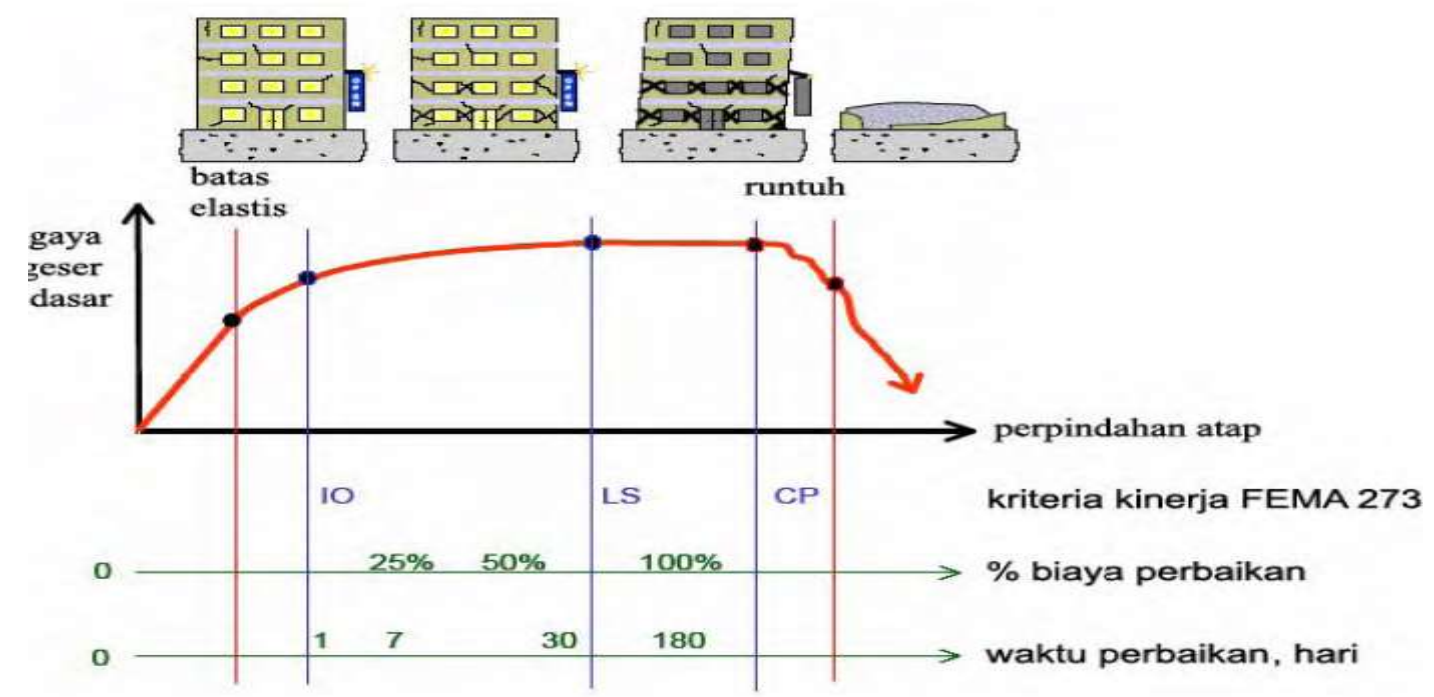

Gambar 1. Ilustrasi Rekayasa Gempa Berbasis Kinerja (ATC 58)

Gambar diatas menjelaskan secara kualitatif level kinerja (perfomance levels) FEMA 237 yang digambarkan bersama dengan suatu kurva hubungan gaya-perpindahan yang menunjukan perilaku struktur secara menyeluruh (global) terhadap pembebanan lateral. Kurva tersebut dihasilkan dari analisa statik non-linier khusus yang dikenal sebagai analisa pushover, sehingga disebut juga sebagai kurva pushover. Sedangkan titik kinerja (perfomance point) merupakan besarnya perpindahan titik pada atap pada saat mengalami gempa rencana, dapat dicari menggunakan metoda yang akan dijelaskan pada bab berikutnya. Kriteria kinerja yang ditetapkan Vision 2000 dan NEHRP adalah sebagai berikut : 
Tabel 1. Kriteria Kinerja

\begin{tabular}{|c|c|c|}
\hline \multicolumn{2}{|c|}{ Level Kinerja } & \multirow[b]{2}{*}{ Penjelasan } \\
\hline NEHRP & $\begin{array}{l}\text { Vision } \\
2000\end{array}$ & \\
\hline Operational & $\begin{array}{c}\text { Fully } \\
\text { Fungtional }\end{array}$ & $\begin{array}{l}\text { Tidak ada kerusakan berarti pada struktur } \\
\text { dan non-struktur,bangunan tetap berfungsi. }\end{array}$ \\
\hline $\begin{array}{l}\text { Immediate } \\
\text { Occupancy }\end{array}$ & Operational & $\begin{array}{l}\text { Tidak ada kerusakan yang berarti pada } \\
\text { struktur,dimana kekuatan dan kekakuanya } \\
\text { kira-kira hampir sama dengan kondisi } \\
\text { sebelum gempa. Komponen non-struktur } \\
\text { masih berada ditempatnya dan sebagian } \\
\text { besar masih berfungsi jika utilitasnya } \\
\text { tersedia.Bangunan dapat tetap berfungsi dan } \\
\text { tidak terganggu dengan masalah perbaikan. }\end{array}$ \\
\hline Life safety & Life Safe & $\begin{array}{l}\text { Terjadi kerusakan komponen } \\
\text { struktur,kekakuan berkurang,tetapi masih } \\
\text { mempunyai ambang yang cukup terhadap } \\
\text { keruntuhan.Komponen non-struktur masih } \\
\text { ada tetapi tidak berfungsi.Dapat dipakai lagi } \\
\text { jika sudah dilakukan perbaikan. }\end{array}$ \\
\hline $\begin{array}{l}\text { Collapse } \\
\text { Prevention }\end{array}$ & $\begin{array}{c}\text { Near } \\
\text { Collapse }\end{array}$ & $\begin{array}{l}\text { Kerusakan yang berarti pada komponen } \\
\text { struktur dan non-struktur. Kekuatan struktur } \\
\text { dan kekakuanya berkurang banyak,hampir } \\
\text { runtuh. Kecelakaan akibat kajatuhan material } \\
\text { bangunan yang rusak sangat mungkin terjadi. }\end{array}$ \\
\hline
\end{tabular}

1 Disampaikan di Civil Engineering National Conference : Sustainbility Construction \& Structural Engineering Based on Professionalism - Unika Soegijapratana,Semarang 17-18 Juni 2005. 
Capacity spectrum method menyajikan secara grafis dua buah grafik yang disebut spektrum, yaitu spektrum kapasitas (capacity spectrum) yang menggambarkan kapasitas struktur berupa hubungan gaya dorong total (base shear) dan perpindahan lateral struktur (biasanya ditetapkan di puncak bangunan), dan spektrum demand yang menggambarkan besarnya demand (tuntutan kinerja) akibat gempa dengan periode ulang tertentu (Gambar 2).

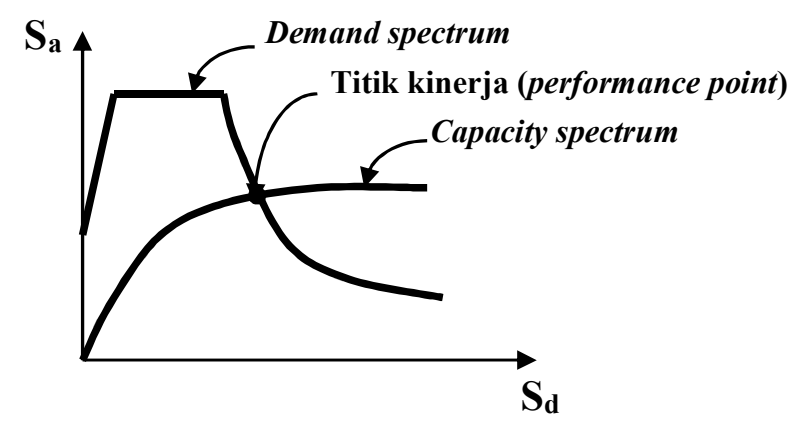

Gambar 2. Performance Point Pada Capacity Spectrum Method

Spektrum kapasitas didapatkan dari kurva kapasitas (capacity curve) yang diperoleh dari analisis pushover. Karena kurva kapasitas merupakan hubungan antara gaya dorong total yang diberikan ke suatu struktur berderajat kebebasan banyak (multi-degree-of-freedom-system, MDOF) terhadap perpindahan yang dipilih sebagai referensi (umumnya puncak bangunan) sedangkan spektrum demand dibuat untuk struktur dengan kebebasan satu (single-degree-of-freedom-system, SDOF), maka kurva kapasitas dengan cara tertentu harus diubah menjadi spektrum kapasitas dengan satuan yang sama dengan spektrum demand. Spektrum demand didapatkan dengan mengubah spektrum respons yang biasanya dinyatakan dalam spektral kecepatan, $S_{a}$, dan Periode, $T$, menjadi format spektral percepatan, $\mathrm{S}_{\mathrm{a}}$, dan spektral perpindahan, $\mathrm{S}_{\mathrm{d}}$. Format yang baru ini disebut Acceleration-Displacemet Response Spectra (ADRS). Kurva kapasitas yang merupakan produk dari pushover dinyatakan dalam satuan 
gaya $(\mathrm{kN})$ dan perpindahan $(\mathrm{m})$, sedangkan demand spectrum memiliki satuan percepatan $\left(\mathrm{m} / \mathrm{detik}^{2}\right)$ dan perpindahan $(\mathrm{m})$. Satuan dari kedua kurva tersebut perlu diubah dalam format yang sama, yaitu spektral percepatan, $S_{a}$, dan spektral perpindahan, $S_{d}$, agar dapat ditampilkan dalam satu tampilan.

Penyajian secara grafis dapat memberikan gambaran yang jelas bagaimana sebuah bangunan merespon beban gempa. Perencana dapat membuat berbagai skenario kekuatan struktur (dengan cara mengganti kekakuan dari beberapa komponen struktur) dan melihat kinerjanya akibat beberapa level demand yang dikehendaki secara cepat dalam satu grafik (Gambar 3). Titik kinerja adalah besarnya perpindahan maksimum struktur saat gempa rencana. Titik kinerja merupakan perpotongan antara spektrum kapasitas dan spektrum demand. Dengan demikian titik kinerja merupakan representasi dari dua kondisi, yaitu: 1) karena terletak pada spektrum kapasitas, merupakan representasi kekuatan struktur pada suatu nilai perpindahan tertentu, dan 2) karena terletak pada kurva demand, menunjukkan bahwa kekuatan struktur dapat memenuhi demand beban yang diberikan.

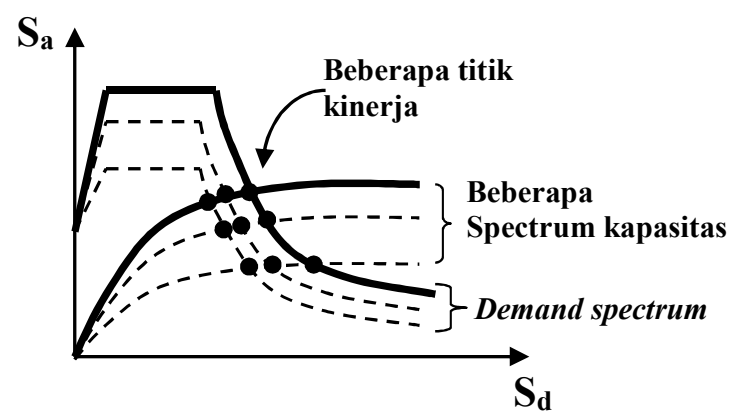

Gambar 3. Beberapa titik kinerja dalam satu grafik dalam CSM

\subsection{Kurva Kapasitas dan Spektrum Kapasitas}

Kurva kapasitas yang didapatkan dari analisis pushover menggambarkan kekuatan struktur yang besarnya sangat tergantung dari kemampuan momen-deformasi dari masing-masing komponen struktur. 
Cara termudah untuk membuat kurva ini adalah dengan mendorong struktur secara bertahap (pushover) dan mencatat hubungan antara gaya geser dasar (base shear) dan perpindahan atap akibat beban lateral yang dikerjakan pada struktur dengan pola pembebanan tertentu (Gambar 4). Pola pembebanan umumnya berupa respon ragam-1 struktur (atau bisa juga berupa beban statik ekivalen) berdasarkan asumsi bahwa ragam struktur yang dominan adalah ragam-1.

\subsection{Spektrum Demand (Demand Spektrum)}

Spektrum demand didapatkan dari spektrum respons elastis yang pada umumnya dinyatakan dalam satuan percepatan, $S_{a}\left(m /\right.$ detik $\left.^{2}\right)$ dan periode struktur, $\mathrm{T}$ (detik). Sama halnya dengan kurva kapasitas, spektrum respons ini juga perlu diubah dalam format ADRS menjadi spektrum demand. Gambar 5 menunjukkan spektrum yang sama yang ditampilkan dalam format tradisional $\left(S_{a}\right.$ dan $\left.T\right)$ dan format ADRS $\left(S_{a}\right.$ dan $\left.S_{d}\right)$. Pada format ADRS, periode struktur yang sama merupakan garis lurus radial dari titik nol. Hubungan antara $S_{a}, S_{d}$ dan $T$, dapat dihitung dengan rumus:

$$
\begin{aligned}
& T=2 \pi \sqrt{\frac{S_{d}}{S_{a}}} \\
& S_{d}=\left(\frac{T}{2 \pi}\right)^{2} S_{a}
\end{aligned}
$$

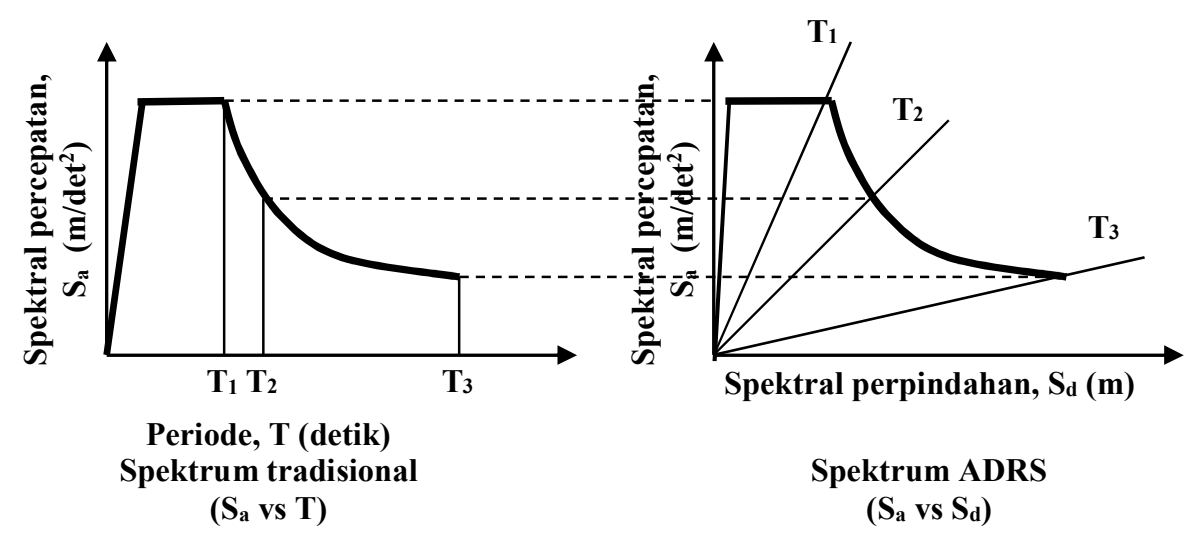

Gambar 4. Spektrum respon yang ditampilkan dalam format tradisional dan ADRS 
Karena pada saat gempa besar telah terjadi plastifikasi di banyak tempat, maka perlu dibuat spektrum demand dengan memperhatikan redaman (damping) yang terjadi karena plastifikasi tersebut. Gambar 6 memberikan penjelasan mengapa terjadi reduksi pada respon inelastis. Titik 1 menunjukkan demand elastis. Jika terjadi reduksi kekuatan struktur akibat perilaku inelastis, periode efektif struktur menjadi semakin besar seperti pada titik 2. Pada kondisi ini, perpindahan bertambah sebesar "a" dan percepatan berkurang sebesar "b".

Jika struktur berperilaku inelastis (nonlinier), pada periode yang sama dengan titik 2 , demand berkurang menjadi spektrum respon inelastis pada titik 3. Jadi, kembali terjadi pengurangan percepatan sebesar "c" dan pengurangan perpindahan sebesar " $d$ ". Total pengurangan percepatan sebesar "b+c" dan perpindahan perlu dimodifikasi sebesar "ad". Jika besarnya "a" diperkirakan sama dengan "d", maka perpindahan inelastis sama dengan perpindahan elastis (Gambar 6a). Jika "a" lebih besar daripada "d" maka perpindahan inelastis menjadi lebih kecil daripada perpindahan elastis (Gambar 6b).

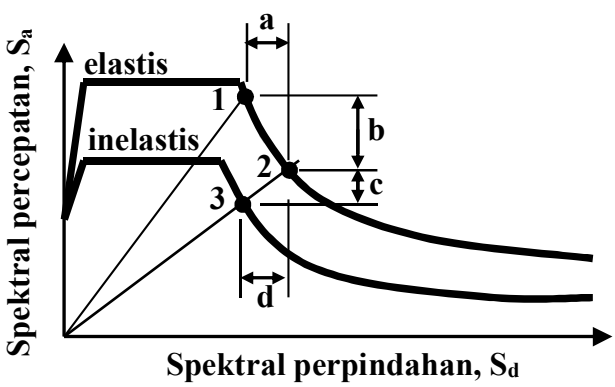

a. Reduksi spektrum respon (Kecepatan konstan, periode yang besar)



b. Reduksi spektrum respon (Percepatan konstan, periode yang kecil)

Gambar 5. Reduksi respon spektrum 


\section{METODE PENELITIAN}

Setelah dimensi awal elemen-elemen struktur masing-masing gedung dan pembebanannya ditentukan, dilakukan analisa push over dengan menggunakan program SAP 2000 V.15



Gambar 6. Diagram Alir Analisa Pushover Pada Bangunan 


\section{HASIL PENELITIAN DAN PEMBAHASAN}

\subsection{Hasil Analisa Pushover Bangunan Portal}

Sasaran kinerja terdiri dari kejadian gempa rencana yang ditentukan (earthquake hazard), dan taraf kerusakan yang diijinkan atau level kinerja (perfomance level) dari bangunan terhadap kejadian gempa tersebut. Mengacu pada FEMA-273 (1997) yang menjadi acuan klasik bagi perencanaan berbasis kinerja maka kategori level kinerja struktur, adalah :

- Segera dapat dipakai $(I O=I m m e d i a t e ~ O c c u p a n c y)$,

- Keselamatan penghuni terjamin ( $L S=$ Life-Safety),

- Terhindar dari keruntuhan total $(C P=$ Collapse Prevention $)$.

- Keruntuhan $(C=$ Collapse $)$

\subsection{Kurva Kapasitas}

Dari proses iterasi didapat kurva kapasitas yang merupakan hubungan antara perpindahan titik acuan pada atap (D) dengan gaya geser dasar $(\mathrm{V})$.

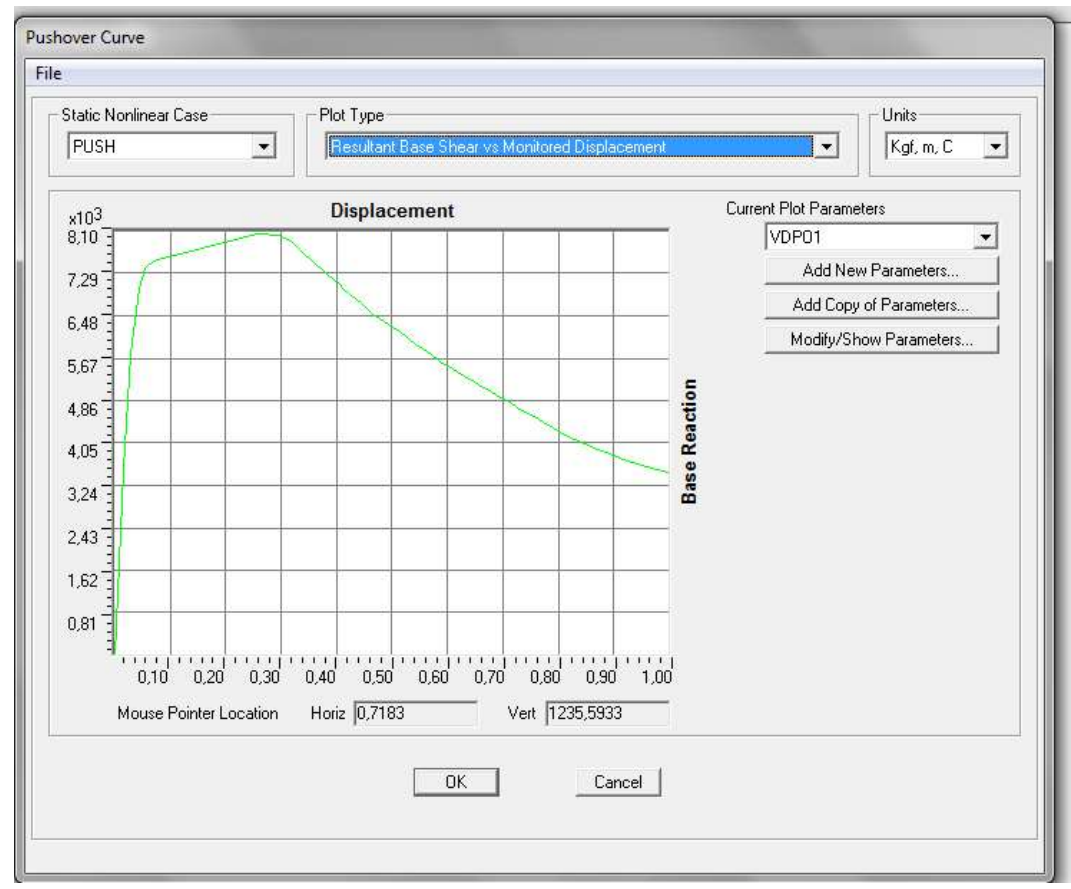

Gambar 7. Base Reaction vs Monitored Displacement 
Grafik menunjukkan pada saat perpindahan mencapai $0,005 \mathrm{~m}$ kondisi struktur masih bersifat elastis yang kemudian berperilaku in-elastis pada saat perpindahan mencapai $0,300 \mathrm{~m}$. Selanjutnya struktur mengalami keruntuhan ditandai dengan penurunan kurva yang tajam.

\subsection{Performance Point.}

Performance point pada kurva kapasitas dan kurva respon spektrum.

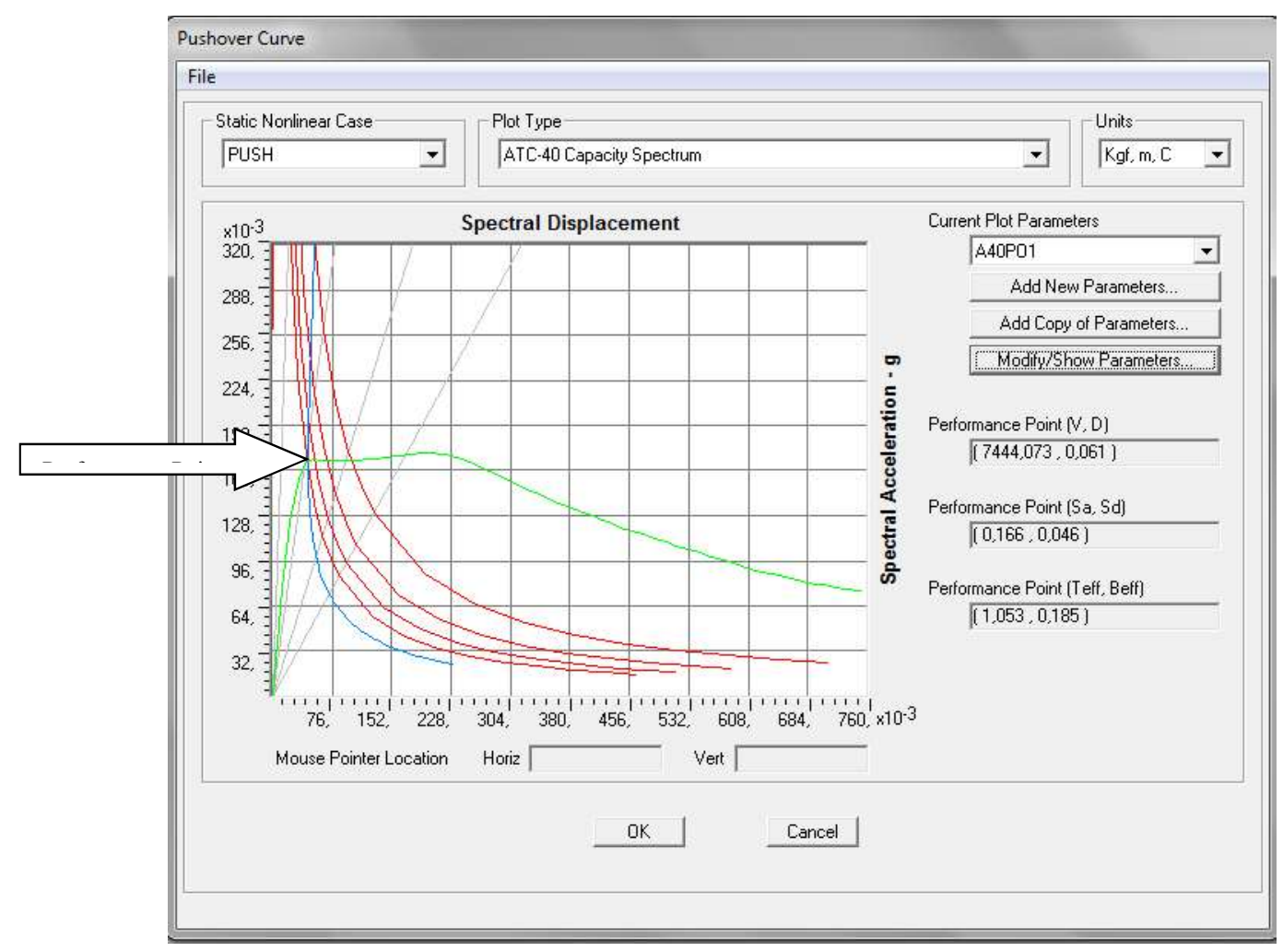

Gambar 8. Performance Point

Tabel 2. Nilai Performance Point

\begin{tabular}{|l|l|}
\hline $\mathrm{V}(\mathrm{Kg}), \mathrm{D}(\mathrm{m})$ & $7444,073 \mathrm{~kg} ; 0,061 \mathrm{~m}$ \\
\hline $\mathrm{Sa}(\mathrm{g}), \mathrm{Sd}(\mathrm{m})$ & $0,166 \mathrm{~g} ; 0,046 \mathrm{~m}$ \\
\hline$T_{\text {eff }}(\mathrm{dtk}), B_{\text {eff }}(\%)$ & $1,053 \mathrm{dtk} ; 0,185 \%$ \\
\hline
\end{tabular}


1. Displacement limit menurut SNI $1726-2002$ ditentukan $2 \% \mathrm{H}=0,02$ x $12=0,24 \mathrm{~m}>\mathrm{D}=0,061 \mathrm{~m}$ maka kinerja displacement gedung baik.

2. Diperoleh gaya geser dasar efektif pada keadaan linear lebih kecil dari nilai geser dasar rencana $\left(\mathrm{V}=7444,073 \mathrm{~kg}<\mathrm{V}_{\text {rencana }}=\right.$ $21784,235 \mathrm{~kg}$ )

3. Kinerja gedung menurut ATC-40 Tabel 11-12

- Maksimal Drift $=D_{t} / H=0,061 / 12=0,00508$

Sehingga kinerja level gedung adalah Immediate Occupancy.

- Maksimal In-elastic Drift $=\left(D_{t}-D_{1}\right) / H_{\text {tot }}=(0,061-0,005) /$

$12=0,00467$

Level kinerja gedung nonlinear adalah Immediate

Occupancy.

\subsection{Skema Distribusi Sendi Plastis}

Tahap pertama, step-0 pada saat nilai displacement 0,005 m. Terjadinya sendi plastis yang berperilaku linear pada tahap ini dimungkinkan karena terjadinya eksentrisitas pada penempatan balok.
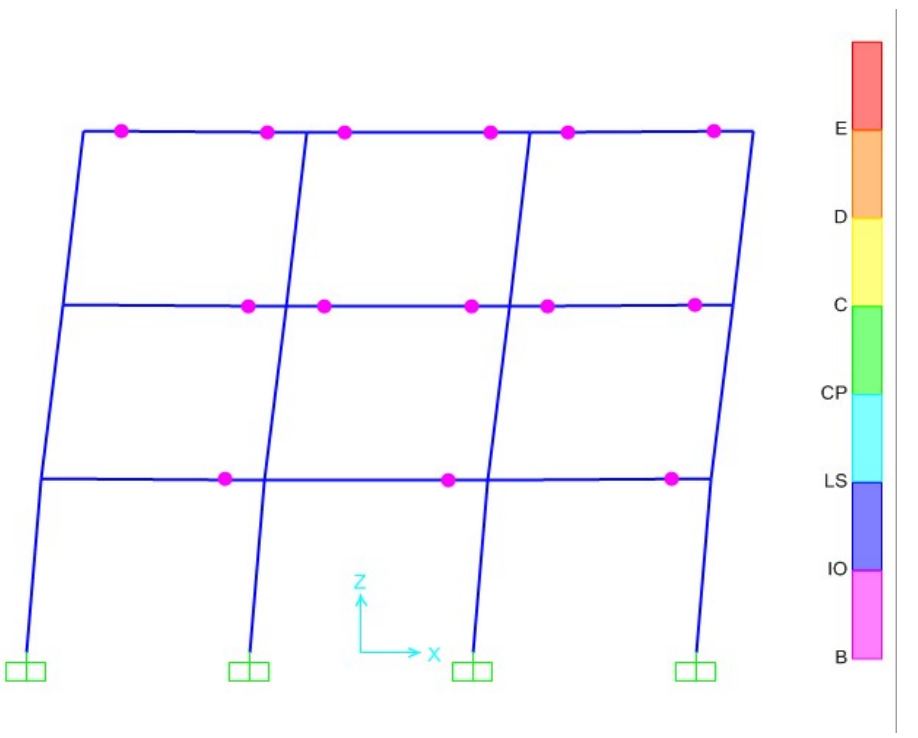

Gambar 9. Step 0 
Seluruh elemen balok pada portal muncul sendi plastis dengan level A-B dan I-O yang mana masih bersifat elastic. Semua ditandai dengan warna merah muda (pink).

Pada step 25, sebagian sendi plastis elemen balok mencapai tahap leleh dengan keadaan struktur balok Collapse dengan ditandai warna kuning terang.



Gambar 10. Step 25

\section{KESIMPULAN}

1. Performance bangunan adalah sebagai berikut :

\begin{tabular}{|l|ll|}
\hline $\mathrm{V}($ Ton), $\mathrm{D}(\mathrm{m})$ & \multicolumn{2}{|c|}{744,073 ton $; 0,061 \mathrm{~m}$} \\
\hline Sa $(\mathrm{g}), \mathrm{Sd}(\mathrm{m})$ & $0,166 \mathrm{~g}$ & $; 0,046 \mathrm{~m}$ \\
\hline Teff $(\mathrm{dtk})$, Beff & $1,053 \mathrm{dtk}$ & $; 0,185 \%$ \\
\hline
\end{tabular}

2. Program SAP 2000 telah menyediakan fasilitas untuk melakukan evaluasi kinerja struktur dengan analisa pushover sesuai ATC-40. 
3. Dengan Metode Analisa Pushover dapat ditunjukkan kinerja bangunan yang telah direncanakan terhadap gempa dengan berbagai periode ulang. Bila kinerja yang dikehendaki tidak dapat dicapai, dengan memperhatikan kerusakan serta letak sendi plastis yang terjadi bagian-bagian tersebut dapat direncanakan kembali dan diperkuat untuk kemudian dilakukan pengujian ulang terhadap kinerja struktur yang telah diperkuat.

4. Konsep desain strong colum weak beam telah terpenuhi. Hal ini ditunjukkan terbentuknya sendi plastis diawali dari elemen balok yang kemudian pada saat mencapai performance point mayoritas elemen balok terbentuk sendi plastis kemudian pada sebagian elemen balok mencapai kondisi batas in-elastis.

\section{DAFTAR PUSTAKA}

1. Departemen Pekerjaan Umum, SNI 1726-2002 Standar Perencanaan Ketahanan Gempa Untuk Struktur Bangunan Gedung.

2. Badan Standarisasi Nasional, SNI 1726-2012 Tata Cara Perencanaan Ketahanan Gempa Untuk Struktur Bangunan Gedung Dan Non Gedung.

3. Handi Pramono dkk, 2007, 12 Tutorial Dan Latihan Desain Konstruksi Dengan SAP 2000 Versi 9, Penerbit ANDI, Yogyakarta.

4. Meher Prasad, 2008, Pushover Analysis, Department of Civil Engineering Indian Institute of Technology Madras.

5. Applied Technology Council, 1996, ATC-40 Seismic Evaluation and Retrofit of Concrete Building, Redwood City, California, U.S.A. 
6. ASCE, 2000, FEMA 356- Prestandard and Commentary for The Seismic Rehabilitations of Buildings, Federal Emergency Management Agency, Washington DC.

7. BBSC, 1995, FEMA 222-NEHRP Recomended Provision for Seismic Regulation for New Building, Washington DC.

8. SEAOC, 1995, Vision 2000 - A Frame Work for Performance Based Earthquake Engineering Vol.1.

9. Yosafat Aji Pranata, 2006, Evaluasi Kinerja Gedung Beton Bertulang Tahan Gempa dengan Pushover Analysis (Sesuai ATC-40, FEMA 356, dan FEMA 440). 